\title{
Jugar al fútbol en la Córdoba (Argentina) de entreguerras: la conformación de subjetividades e identidades en el deporte
}

\author{
Playing Football In The Inter-War Period \\ In Cordoba (Argentina): The Formation of \\ Subjectivities And Identities In Sport
}

\author{
Franco D. Reyna \\ (D) 0000-0003-3930-0572 \\ Universidad Nacional de Córdoba, Argentina \\ Instituto de Estudios Históricos-Centro de \\ Estudios Históricos "Prof. Carlos S. A. Segreti" \\ franco2reyna@hotmail.com
}

Resumen: El trabajo reconstruye las distintas experiencias de los jugadores alrededor de la práctica del fútbol en la Córdoba (Argentina) de los años veinte y treinta, a fin de aprehender los cambios en la subjetividad de los actores y los modos a través de los que fueron estructurando sus identidades. Para dar cuenta de ello, el artículo analiza el fútbol como práctica de socialización y se adentra en los valores, comportamientos y sentidos de pertenencia que los futbolistas pusieron en juego en sus trayectorias deportivas, tanto dentro del amateurismo como del profesionalismo. En este sentido, el fútbol vivió en la época un proceso de espectacularización y mercantilización que conllevó transformaciones en las formas en las que los sujetos construyeron sus cambiantes y fragmentarias identidades e intervinieron en el ámbito deportivo. Las principales fuentes que se utilizaron fueron la prensa periódica de la época y documentos pertenecientes a asociaciones deportivas locales.

Palabras clave: fútbol; espectáculo; mercantilización; subjetividades; identidades. 
Abstract: The article reconstructs the different experiences of the players regarding the practice of soccer in Cordoba (Argentina) in the 1920s and 1930s, in order to capture changes in the subjectivity of the actors and the ways they structured their identities. In order to describe this, the article analyzes football as a socialization practice and explores the values, behaviors and sense of belonging football players put into practice during their sporting careers, both amateur and professional. In this respect, during this period, football underwent a process of spectacularization and commodification that led to transformations in the ways individuals constructed their changing and fragmentary identities and engaged in sports. The main sources used were the periodical press of the time and documents belonging to local sports associations.

Key words: football; show; commodification; subjectivities; identities.

Fecha de recepción: 11 de enero de 2016 Fecha de aceptación: 17 de septiembre de 2016

\section{INTRODUCCIÓN}

$\mathrm{D}$ urante las décadas de 1920 y 1930, el fútbol local experimentó un paulatino proceso de espectacularización, que implicó una serie de transformaciones en los contenidos de la cultura de masas cordobesa. En efecto, simultáneamente a su expansión como ejercicio físico, la práctica deportiva se fue desarrollando como una actividad representada ante un público como respuesta a necesidades de distinto tipo, desde rituales de integración a mecanismos de mitigación o canalización de tensiones o mero esparcimiento (Baker y Castro, 2008, p. 13). Para ello, debió atravesar procesos de normativización e institucionalización de sus estructuras, especialización de roles entre sus actores, sistematización y regularización de calendarios competitivos y construcción de escenarios urbanos para contener a los espectadores. Esto conllevó la progresiva mercantilización del ocio de las masas, es decir, la formación de un mercado deportivo como producto cultural de masas consumido por cada vez más sectores de la población. En ese marco, los futbolistas compartieron una experiencia común en torno al juego como práctica socializadora y emplearon una diversidad de registros materiales y simbólicos para significar sus interacciones y pertenencias tanto en el amateurismo como en el profesionalismo. 
Al respecto, el artículo explora los sentidos que se le daba a jugar al fútbol en esta época y las expectativas que generaba, a la vez que se adentra en las trayectorias de los jugadores para retratar sus valores y comportamientos e identificar los diferentes vínculos que articularon con otros actores y con las estructuras de poder en el ámbito deportivo. El objetivo es aprehender las experiencias y los cambios en la subjetividad de estos actores, es decir, cómo vivieron, sintieron y se representaron en esta práctica y las formas a través de las que fueron estructurando sus identidades individuales y colectivas de maneras cambiantes y fragmentarias, una temática inédita en la historiografía local.

Como sostienen Bolufer y Morant (2012, pp. 319-320), los estudios contemporáneos han rechazado la visión esencialista de la identidad asociada a unos atributos innatos y compartidos (como sexo, raza, nación) o la idea que atribuía su origen a condiciones comunes de experiencia material (clase) y actualmente impera su concepción como una construcción social que asume caracteres múltiples, contradictorios y atravesados por diferencias internas. $\mathrm{Al}$ respecto, las identidades se refieren a la posición que cada sujeto adopta en su relación con los otros con los que interactúa cotidianamente y en las que se ponen en juego sus proyectos, sus necesidades y sus deseos; alude a los sentimientos de pertenencia de los agentes sociales a determinados grupos o colectivos humanos y puede visualizarse empíricamente en las expectativas y códigos que estos ponen en funcionamiento cuando se embarcan en acciones comunicativas (Kaliman, 2013, pp. 149-151). Las nociones o sentimientos de pertenencia están presentes en la experiencia y la subjetividad de los agentes y son vividos como una realidad de su saber práctico desde el momento en que estos comparten un modo de interpretar la realidad y de actuar conforme a esa interpretación en contextos específicos (Kaliman, 2013, pp. 118-120). En este contexto, la subjetividad tiene un carácter socialmente situado y debe entenderse como un acto de mediación que incorpora, por una parte, las posiciones asignadas al sujeto por los discursos y, por otra, la experiencia de quienes son construidos o interpelados por los discursos, entendiendo la experiencia como algo mediatizado por valores y conceptos previos (Bolufer $y$ Morant, 2012, p. 324).

El fútbol es un escenario privilegiado para la producción de identidades, sean de pertenencia o de rol, en una dinámica dialéctica entre reforzamiento y reelaboración de sentidos y lealtades que opera contextualmente y que, bajo ciertas condiciones, es susceptible de transformación (Villena Fiengo, 2003, p. 26). A través del estudio de las experiencias de los sujetos en el 
fútbol cordobés de entreguerras se pueden analizar las imágenes que construyeron de sí mismos y los demás en la práctica, sus relaciones y posiciones en el entramado deportivo, los sentidos de pertenencia y afinidad que edificaron y las formas en que los otros los interpelaron y categorizaron dentro de los condicionantes estructurales de la época. En esa reconstrucción se intentarán divisar algunas de las fragmentadas, plurales y cambiantes identidades en juego en la práctica deportiva, que dado su carácter contingente se reordenan y rejerarquizan continuamente en el flujo de la vida social y en función de las estrategias vitales de los propios sujetos (Pérez Ledesma, 2008, p. 25).

La principal fuente que se utilizó para dar cuenta de esta problemática fue la prensa periódica de la época, acompañada por algunos documentos pertenecientes a asociaciones deportivas locales existentes en repositorios propios o gubernamentales. El análisis indiciario sobre ellos ha tratado de captar las interacciones y pertenencias de los sujetos a través de registros dispersos y las afirmaciones que se proponen, constatadas empíricamente a partir de ejemplos de casos o derivadas del estudio de masas documentales, son fragmentarias, temporales, circunstanciales y pragmáticas, sobre todo al tratar objetos tan complejos, imprecisos u opacos para la aprehensión del historiador como las emociones, los sentimientos, las identidades, etcétera.

En definitiva, el análisis del proceso de conformación de subjetividades e identidades en la práctica del fútbol es una vía de entrada para construir una mirada un poco más compleja del proceso de modernización de la ciudad y el modo en que los sujetos lo experimentaron.

\section{EL FÚTBOL COMO PRÁCTICA DE SOCIALIZACIÓN}

"La debilidad más grande de mi vida es el fútbol." Quizás exageradas por las circunstancias, esas breves palabras ante un requerimiento de la prensa resumían el sentir de uno de los tantos aficionados anónimos que se movían al compás de la práctica deportiva en la ciudad a mediados de los años veinte. Por entonces, el fútbol consolidaba su posición en la esfera social y se imponía entre las preferencias del emergente mercado de entretenimientos urbanos de los cordobeses. Mientras aprendían el juego en cualquier espacio al aire libre, muchos niños crecían anhelando asociarse a un club y convertirse

\footnotetext{
${ }^{1}$ La Voz del Interior, 1 de marzo de 1927, p. 14.
} 
en jugadores de fútbol. En la identificación con una práctica deportiva, un territorio, un club y un colectivo transitaba una parte importante de la experiencia citadina de muchos varones.

Los años de entreguerras sentaron las bases para la transformación del fútbol en la ciudad como un espectáculo de masas. El gran crecimiento demográfico y urbano en el periodo, la bonanza económica que atravesó el país en los años veinte, la mayor disposición de tiempo libre de los trabajadores gracias a las conquistas obreras y a los procesos de tecnificación resultantes de la segunda revolución industrial y el acceso masivo de los habitantes a la instrucción pública (Ortiz Bergia, Reyna, Portelli y Moretti, 2015) fueron aspectos que, entre muchos otros, propiciaron que diferentes sectores de la población accedieran al consumo de actividades de ocio urbano, principalmente el fútbol. En efecto, aumentó el número de equipos y categorías en la Liga Cordobesa de Fútbol (LCF), la entidad rectora de las competencias del fútbol oficial cordobés, ${ }^{2}$ a la par que creció considerablemente la cantidad de clubes que se fundaron en el circuito del fútbol aficionado, por fuera del oficial representado por la LCF $;{ }^{3}$ hubo un franco incremento en la cantidad de asociados a los clubes; ${ }^{4} \mathrm{y}$ el número de asistentes tuvo un constante crecimiento. ${ }^{5}$ Esto fue acompañado, a su vez, por la ampliación de las estructuras asociativas de las entidades con la incorporación de nuevos deportes, de una serie de servicios sociales y mutuales (como la atención médica) y de espacios recreativos y culturales como bailes, bibliotecas, talleres para beneficio no sólo de los socios, sino de toda la comunidad barrial donde estaban insertos (Reyna, 2015).

De esta manera, el fútbol se generalizó en esa época como una práctica habitual de muchos niños y jóvenes cordobeses. La experiencia de jugar y asociarse aparecía como elemento clave en su proceso de socialización. Los reunía con sus pares, les forjaba un hábito, les enseñaba a asumir compromisos y a respetar reglas, los instaba a organizarse y tomar decisiones, los proveía de

${ }^{2}$ Si en 1920 había 76 equipos divididos en siete categorías, en 1930 eran 168 y 17 respectivamente.

3 Entre 1920 y 1943 se crearon más de 300 equipos.

4 Entre 1917 y 1926, el índice de crecimiento superó el 400\% en algunas entidades como Talleres, Universitario y Alem.

${ }^{5}$ Como punto de referencia, los encuentros clásicos entre Belgrano y Talleres hacia mediados de los años veinte llegaban a convocar hasta 8000 personas. En 1929 y 1931, respectivamente, estas entidades construyeron los primeros estadios de cemento de la ciudad para contener las concurrencias multitudinarias a los grandes eventos deportivos de la época, con capacidad de hasta 10000 y 15000 personas. 
una meta y modelos a seguir y los llevaba a intervenir sobre el espacio urbano. Esas nuevas camadas de muchachos, a diferencia de los pioneros, aprendieron el deporte desde temprana edad y bajo el arquetipo de la práctica orgánica ya estructurada, que representaba el horizonte anhelado por muchos de ellos. Transmitida por sus padres o por la misma experiencia barrial, ya desde entonces incorporaban la adhesión por algún club en particular y movilizaban sus primeras identificaciones colectivas.

Un par de esos niños entusiastas de la práctica callejera fueron interrogados por cronistas urbanos en relación con su afición por el deporte y manifestaron sus expectativas en torno al fútbol organizado. Juan Leguizamón, un lustrabotas de once años simpatizante del club Belgrano, tenía la esperanza de juntar el monto de dinero necesario para pagar el importe de la cuota mensual para ser socio del "equipo de sus amores". Pinocho, un simpatizante del club Audax, se presentaba afirmando "paso a tercer grado, cuento 8 años de edad y pienso ser un crack"; ${ }^{6}$ esperaba llegar a la edad de doce para poder ingresar y vestir la camiseta de la institución en quinta división. Así como ellos, el anhelo deportivo de muchos niños pasaba por reunir las condiciones para que, llegado el momento, pudieran pasar a formar parte del club con el que se identificaban como socio y/o jugador de sus divisiones inferiores. La pertenencia asociativa era apreciada como un medio de integración social y se transformaba en uno de los rituales de pasaje a través de los que esos muchachos dejaban de ser niños y comenzaban a asumir responsabilidades más asociadas a la vida adulta, como las que implicaba la participación en una entidad. Asimismo, la idea del éxito personal también definía la proyección identitaria de los niños deportistas; en el horizonte de sus aspiraciones imaginaban una carrera exitosa como la de los cracks que triunfaban en los clubes de su preferencia, pero para reforzar los elencos del fútbol organizado debían pasar por un proceso de selección de talentos.

\section{EL TRAYECTO DEPORTIVO DE LOS JUGADORES}

En los diferentes reportajes que los diarios locales realizaban a los futbolistas locales ya consagrados, la gran mayoría reconocía que sus inicios en el juego estuvieron ligados a la calle y el baldío junto a los compañeros del colegio o

${ }^{6}$ La Voz del Interior, 10 de diciembre de 1930, p. 3, y 15 de diciembre de 1930, p. 3. 
el vecindario. Más allá de la veracidad de la afirmación, esa idea respondía también a una representación común al conjunto de los jugadores que esencializaba un origen compartido: "Como todos, la génesis del footballer exige el paso obligado del football 'liliputiense', si llamarse puede así al que se practica con pelota de trapo y en un sitio baldío."

Ese espacio -el baldío- fue posteriormente transformado por la cultura y reivindicado hacia finales de los años veinte como "potrero", un territorio concreto sin demarcaciones estipuladas donde se jugaba de manera espontánea, despojado de infraestructuras básicas y que tenía una condición periférica en relación con los campos de juego y estadios oficiales. ${ }^{8}$ Los jugadores se apropiaron de ese espacio y lo identificaron como inherente a su práctica. Además de su contenido espacial, suponía también la concreción de una experiencia mítica, simbolizada en el aprendizaje del fútbol de manera informal, anárquico, sin órdenes ni posiciones fijas, ni ninguna supervisión institucional. El potrero era el momento de iniciación dentro del trayecto modélico construido en torno a la formación de los jugadores; empezaban desde abajo para terminar luego en las grandes ligas y, en algunos casos, percibiendo remuneraciones por su concurso. En ese ejercicio de rememoración, algunos futbolistas evocaron datos de su peregrinar deportivo que sirvieron para elaborar un imaginario compartido por todos, cargado de contenidos nostálgicos y emotivos. En palabras de Romero (1995), los actores de un proceso histórico como este se constituyen en el entrecruzamiento de las situaciones y sus representaciones, del que surge su identidad.

$\mathrm{Al}$ respecto, luego del paso "obligado" del potrero, la ruta ascendente continuaba con el ingreso - una vez que tenían la edad necesaria, sin pasar el tope reglamentario de los quince años- a las quintas divisiones de los clubes cercanos a sus áreas de residencia que estuvieran inscritos en la LCF. Desde entonces, si se destacaban por sus destrezas y valentía, iban escalando de categoría hasta llegar a primera cuando rondaban las dos décadas de vida. Los

${ }^{7} \mathrm{La}$ Voz del Interior, 21 de agosto de 1926, p. 14. Quien no había tenido ese aprendizaje era tratado como una excepción a la norma, como el caso de Adolfo Ríos, zaguero de Palermo a quien comenzó a gustarle el juego recién a los 20 años cuando hizo el servicio militar. Los Principios, 4 de septiembre de 1941, p. 9.

${ }^{8}$ Según Archetti (2008), la asociación remite a que, en una época en que la imagen del gaucho se impuso en la narrativa nacional, lo que la pampa representaba para el gaucho como espacio no domesticado por la agricultura donde podían moverse libremente, el potrero lo era para el pibe. 
que quedaban en el camino por selección o elección, pero seguían viendo en el fútbol un medio de entretenimiento, permanecían actuando en las divisiones inferiores de los clubes de la LCF o pasaban a engrosar las filas de las entidades del fútbol aficionado. A pesar de representar a la gran mayoría de los jugadores, sus derroteros están pobremente documentados, a diferencia de quienes alcanzaron a jugar en las divisiones más altas y disfrutaron de una mayor atención periodística.

El recorrido ascendente no siempre se hacía con los mismos clubes, ya que podían cambiar de equipo si desaparecía aquel en el que estaban o si el nuevo destino les ofrecía mejores perspectivas. El andar errante de Pablo Sosa, jugador de Lavalle, puede ilustrar la premisa: se había iniciado en 1922 en la quinta división del extinguido Fomento, para pasar luego a la cuarta de Talleres y a la tercera de Audax. Más adelante firmó para Lavalle, donde jugó tres años y pasó a Barracas por un año, tras lo cual debió abandonar la ciudad por trabajo para trasladarse a la localidad de Villa María, donde actuó por Unión Central. $\mathrm{Al}$ año volvió a Barracas para luego ser transferido definitivamente a Lavalle. ${ }^{9}$

Una gran parte de los jugadores se iniciaba en entidades independientes del fútbol aficionado barrial o de la campaña para desde ahí pegar el salto "con que todos los purretes soñamos"10 y abastecer a los clubes del circuito oficial. A veces, eran socios o allegados de uno de esos últimos quienes los "descubrían" y los conminaban para incorporarse al mismo. Por citar un caso, Pedro Giacomelli se había formado como jugador en los baldíos del Barrio Inglés; Miguel A. Tobler, dirigente de Talleres, lo observó al pasar en uno de esos "picados" y lo invitó a firmar por el club, en el que llegó a tercera división. ${ }^{11} \mathrm{~A}$ veces, la participación en el fútbol independiente y el oficial se iba alternando. Así quedaba revelado en la trayectoria de Francisco Giordano, quien, como la gran mayoría, dio sus primeros pasos en los potreros citadinos; cuando tenía trece años, probó suerte con unos compañeros en Huracán y fue seleccionado, debutando en la quinta división del club. En 1933, llamado por unos amigos del barrio, pasó a integrar el conjunto de Chacabuco dentro de la Asociación Amateurs. Al disolverse en 1935, volvió a la segunda de Huracán, donde permaneció hasta 1937. Después Belgrano lo compró, actuó en la intermedia y algunos partidos en primera, pero no pudo amoldarse al

\footnotetext{
9 Los Principios, 19 de diciembre de 1935, p. 9.

$10 \mathrm{La}$ Voz del Interior, 3 de enero de 1942, p. 12.

${ }^{11} \mathrm{La}$ Voz del Interior, 27 de junio de 1935, p. 14.
} 
equipo y, al quedarse sin puesto, Sportivo Alta Gracia, club de la localidad homónima, logró su concurso. Fue sólo una temporada, pues el jugador quería actuar en su ciudad; entonces Bolívar consiguió el pase y jugó allí hasta 1940, para pasar después a Instituto, en calidad de préstamo, que era donde se encontraba al momento de la nota. El jugador temía que, al pasar por muchos clubes, se lo acusara de "golondrina" o de no sentir afecto por los colores que defendía, por lo que aclaraba que sólo quería jugar al fútbol, sea cual fuere el conjunto $y$, cuando lo hacía, por modesta que fuera la institución, siempre ponía toda su voluntad, celo y cariño. Agregaba que Instituto era el club de sus amores y siempre fue su anhelo actuar en defensa de sus colores, ya que de chico seguía al club y quería emular a sus grandes figuras. ${ }^{12}$

Las palabras de Giordano abren otras lecturas. Por un lado, durante los años veinte, con la expansión del amateurismo marrón (profesionalismo ilegal), persistió y se incrementó el nomadismo deportivo, es decir, los constantes traspasos de jugadores de un club a otro en búsqueda de mejores posibilidades. Esta movilidad de los futbolistas ya no sólo tenía entre sus principales razones la frecuencia con que desaparecían clubes y se fundaban otros nuevos, sino que ahora estaba motivado también por las gratificaciones materiales (en dinero, trabajo o vestimentas de juego) que comenzaban a recibir los jugadores para incorporarse a entidades que buscaban mejorar su competitividad. Su acepción peyorativa, el "golondrineo", comprendía a los que, en este marco y salvo situaciones forzosas, especulaban con cambiar repetidamente de equipo para partir al mejor postor, que les ofrecía mejores condiciones deportivas y económicas. Incluso cuando ya se había oficializado la práctica rentada (el profesionalismo, sancionado en 1933), esta figura seguía actuando como referencia negativa para juzgar a los futbolistas que no buscaban en el fútbol un motivo de sano esparcimiento y de ejercicio de la cultura física y se "dejaban dominar por el mercantilismo", demostrando una falta de afecto por los colores de un club. Todos los futbolistas buscaban defenderse de ese mote porque implicaba una afrenta a su honor. Ya lo remarcaba Pedro Saldaño al contar su vida deportiva: "no soy partidario de los 'golondrinas': desde que me inicié en el deporte no he firmado nunca ni pienso hacerlo un pedido de pase. Sólo pasé a Instituto cuando dejó de existir el club de los Nicola [Escuela de Comercio]." ${ }^{13}$ La eficacia discursiva de este tipo

${ }_{12}^{12}$ La Voz del Interior, 3 de enero de 1942, p. 12. 
de representaciones que afectaban el honor personal en el deporte constituía sujetos que internalizaban esas identidades y eran influidos en los usos que hacían de las normas y estructuras en las que estaban insertos.

Uno de los factores que alimentaba el continuo pasaje de futbolistas era el anhelo de poder jugar en las categorías superiores del fútbol oficial y, de ser posible, hacerlo en los clubes con los cuales simpatizaban, pero pocos gozaban de esa suerte. Elección mediante de dar ese salto, la mayoría se acomodaba donde el naciente mercado de talentos los colocara. Como ha señalado Frydenberg (2011), ese mercado regido por una fuerte selectividad se conformó en un contexto de desarrollo del jugador especialista-talentoso, que tenía pleno dominio de las técnicas deportivas y de la capacitación física. En ese marco, sostiene el autor que la afectividad de los jugadores "con los colores" quedó afincada en ese momento épico previo a su ingreso en el mundo competitivo del fútbol oficial.

De allí que la mayoría de los jugadores se fuera desprendiendo progresivamente del ideal romántico de jugar en el club en el que se habían formado y por el que expresaban afecto: jugaban para un equipo al mismo tiempo que simpatizaban por otro. A veces, incluso, seguían siendo socios de una entidad, por más que estuvieran jugando en otra: Rogelio Escatena se había formado en Talleres y en 1927, por gestión de unos amigos, se pasó a Audax, para retornar en 1931 a su club de origen, del que seguía siendo socio y por cuyos colores "se jugaba entero"..$^{14}$ José Jover se había iniciado en Lavalle, pero implantado el profesionalismo fue contratado por Audax, con el que siempre había simpatizado. ${ }^{15}$ Tampoco era sólo una coincidencia que muchas veces el entrevistado declarara su afición por el club en el que se estaba desempeñando, lo cual era una forma también de legitimar su estadía y conseguir el aval de los aficionados. Dentro de sus márgenes de acción, los jugadores alteraban identidades deportivas primigenias que se pretendían inmutables y forjaban nuevos sentidos de pertenencia para adaptarse a las coyunturas que les planteaba la práctica deportiva.

${ }^{14}$ Los Principios, 11 de junio de 1933, p. 17.

${ }^{15}$ Los Principios, 21 de abril de 1934, p. 9. 


\section{Las estrellas del amateurismo}

El deseo de los jóvenes de convertirse en jugadores de fútbol y de pertenecer al grupo de elite, la configuración de un mercado deportivo que priorizaba a los talentos individuales y el interés de la prensa por crear figuras de consumo popular alimentaron la emergencia de nuevos cracks del mundo deportivo.

Este era un modelo del jugador destacado que sobresalía por sus habilidades, destrezas y coraje en un campo de juego y que la hinchada lo ungía y lo convertía en emblema popular al vitorear su nombre en público, llevarlo en alzas y seguirlo a cada paso. La prensa acompañaba esa evolución y arropaba de un carácter simbólico a su figura como brazo ejecutor especializado de las aspiraciones deportivas de la afición, contribuyendo con ello al realce del espectáculo. A la vez, aunque eran la excepción, incorporaba otros candidatos a esta condición: aquellos que se consagraban sin un historial marcado por esos grandes episodios que la masa aficionada recordaba, sino por su regular desempeño y fuerte compromiso con el equipo, como el caso de Pedro Giacomelli en Audax. ${ }^{16}$ De otros como Emilio Castro, cuya mayor satisfacción la había experimentado durante un partido contra Belgrano cuando la hinchada de Talleres lo hizo objeto de una calurosa demostración de simpatía, se decía que se habían ganado la estima de los dirigentes, hinchas y socios del club por su carácter modesto y reservado, sin las ínfulas que gastaban muchos de los que se sentían jugadores de elite y que podía llevarlos a la ruina. ${ }^{17}$

En efecto, desde el momento en que se generalizó el amateurismo marrón, una parte de estos jugadores fue dotado de una connotación negativa por su carácter disruptivo del jugador vinculado con los valores de la deportividad inglesa, ya que alrededor de ellos se construía una imagen generalizada de jóvenes pretenciosos, altaneros, individualistas e interesados, que imponían condiciones a los dirigentes para contar con su concurso deportivo ( $\mathrm{Di}$ Giano, 2004, p. 215).

Este discurso fue difundido desde la prensa con un fin aleccionador y moralizador, pero también fue utilizado en contraposición por otros deportistas para validar sus propias trayectorias deportivas. En efecto, algunos de los jugadores pioneros en el fútbol local, que ya mediando los años veinte se habían retirado de la práctica activa, evocaban su pasado deportivo en términos

\footnotetext{
${ }^{16}$ La Voz del Interior, 27 de junio de 1935, p. 14.

${ }^{17}$ Los Principios, 19 de mayo de 1935, p. 16.
} 
de tiempos heroicos y honorables, valiéndose de una construcción de su presente que remitía a una otredad con la que marcaban distancia por su carácter mercantilista. Santiago Bolognino y Abel Fiorelli ${ }^{18}$ aseveraban que entonces se jugaba con un "espíritu superior", que refería a ese entusiasmo por resultar airoso en la defensa de los colores del club derrochando generosamente todas las energías para triunfar o sucumbir con honra, una virtud indispensable al fútbol que había desaparecido. El futbolista, seguían afirmando los entrevistados, había incorporado desde sus raíces esos valores y se llenaba de privaciones "para forjar en la palestra la gloria de la institución que nos cobijaba. No queríamos recompensa ni la buscábamos nunca porque en esos años era una pasión el cultivar el popular deporte." ${ }^{19}$ Asimismo, criticando los procederes de muchas de las nuevas figuras deportivas vigentes, aseguraban que

era muy rara la vez que se nos llevaba en coche y desde las casas. Acudíamos las más de las veces a patacón por cuadra y éramos más puntuales y asiduos. De "motu propio" se asistía entre la semana a los fields, pues los prestigios del club por el cual nos interesábamos reclamaba nuestro esfuerzo. Nuestros beneficios eran muy superiores: una victoria o la satisfacción de ser vencidos después de emplear todo nuestro esfuerzo eran la mejor recompensa. ${ }^{20}$

Con el auspicio de la prensa, los jugadores fueron construyendo una imagen mítica de esa época inaugural del fútbol como premisa para elaborar una crítica a la "degradación" mercantilista de esos tiempos modernos: la labor inicial para la edificación de una práctica sustentada en la entrega desinteresada y la honorabilidad de los participantes por un fin colectivo iba deviniendo progresivamente en una experiencia individualista preocupada por el éxito deportivo y el posicionamiento económico. Sin embargo, esta concepción fue sufriendo alteraciones conforme se iba extendiendo la práctica del amateurismo marrón a finales de los años veinte y principios de los treinta, en consonancia con las transformaciones que fue experimentando el fútbol en sus estructuras.

Tan rápido como se los convertía en ídolos, se los transformaba en figuras mediáticas. Paulatinamente, los jugadores se iban convirtiendo en celebridades

\footnotetext{
${ }^{18}$ La Voz del Interior, 21 de septiembre de 1926, p. 14 y 18 de agosto de 1926, p. 14.

${ }^{19} \mathrm{La} \mathrm{Voz} \mathrm{del} \mathrm{Interior,} 21$ de septiembre de 1926, p. 14.

${ }^{20} \mathrm{La} \mathrm{Voz}$ del Interior, 18 de agosto de 1926, p. 14.
} 
reconocidas por el público deportivo: "al hablar de campeones, parecemos estar ante personajes de leyenda. Muy pocos ignoran su biografía”. ${ }^{21}$ Sus imágenes ilustraban las páginas deportivas y había un interés creciente por presentar al público aspectos de sus vidas fuera de la cancha de fútbol. Al respecto, hacia septiembre de 1930, el periódico La Voz del Interior inició una sección donde mostraba a algunos cracks locales insertos en su vida laboral o estudiantil. Eran jugadores de mucho renombre deportivo en la ciudad, de los que no se conocía mucho en relación con su faceta más cotidiana. Los primeros en pasar por esa sección fueron tres jugadores de Instituto: los dos primeros, Bernardo Fernández y Arturo Días, se desempeñaban desde hacía varios años en el Ferrocarril Central Córdoba como guardatrén y en el transporte de bultos al servicio de la oficina de Encomiendas y Equipajes, respectivamente; el último, Santiago Narvaja, trabajaba en la Cervecería Córdoba ${ }^{22}$ y al año siguiente fue el primer futbolista cordobés en profesionalizarse, siendo célebre su secuestro cuando marchó de Nacional de Rosario a Boca Juniors de Buenos Aires. ${ }^{23}$ Otros de los entrevistados fueron Ignacio Romero, de Belgrano, que llevaba diez años trabajando como escribiente en la Tesorería de la Provincia de Córdoba; ${ }^{24}$ Federico Pérez, de Juniors, quien era tenedor de libros en la Oficina de Cuentas Corrientes de la Compañía General de Electricidad, además de aficionado al canto; ${ }^{25}$ y Rogelio Freytes, de Belgrano, quien pertenecía desde un año atrás al personal del Banco Alemán Transatlántico como auxiliar de caja. ${ }^{26} \mathrm{~A}$ ellos se sumaban los estudiantes universitarios como José María García, de Universitario, y Mauricio Waisman, de Juniors, quienes seguían la carrera de matemáticas en la Facultad de Ingeniería. ${ }^{27}$

Con base en esos ejemplos se intentaba desmitificar la visión del deportista como un hombre improductivo e indisciplinado fuera de las canchas de fútbol. Para poder ser convertido en producto cultural de consumo masivo, la figura del crack comenzó a ser realzada de nuevas significaciones que transformaron su perfil identitario. Más bien, imponía una nueva imagen del futbolista que era compatible con su papel como trabajador y destacaban el

\footnotetext{
${ }^{21}$ La Voz del Interior, 23 de enero de 1927, p. 14.

${ }^{22} \mathrm{La}$ Voz del Interior, 16 de septiembre de 1930, p. 8.

${ }^{23} \mathrm{La}$ Voz del Interior, 13 de diciembre de 1932, p. 13.

${ }^{24} \mathrm{La}$ Voz del Interior, 20 de septiembre de 1930, p. 16.

${ }^{25} \mathrm{La}$ Voz del Interior, 19 de octubre de 1930, p. 16.

${ }^{26} \mathrm{La}$ Voz del Interior, 20 de noviembre de 1930, p. 16.

${ }^{27} \mathrm{La}$ Voz del Interior, 30 de octubre de 1930, p. 15.
} 
valor del entrenamiento del músculo como forjador de aptitudes para encarar la "lucha diaria por el sustento", como un espacio de formación de la mano de obra, desde donde también contribuían a la "grandeza de la patria". ${ }^{28}$ Por otro lado, no dejaba de ser este un ejercicio pedagógico en tiempos de amateurismo "marrón", ${ }^{29}$ con miras a enseñar a los jugadores la precariedad y fugacidad del fútbol como medio de vida y la importancia y necesidad de aprender oficios y profesiones y buscar formas de subsistencia más seguras. La práctica deportiva no se desprendía de su concepción como medio de esparcimiento.

Por otro lado, el estatus de estrella deportiva lejos estaba de ser inmutable en el marco de una institución, ya que podían ser destronados de ese lugar si se cambiaban de club o dejaban de responder a las pretensiones de los aficionados y directivos, aun cuando su capacidad y voluntad no estuvieran en discusión. En tanto identidad fluctuante, debía ser constantemente reafirmada. Una vez que dejaban la práctica activa del fútbol, sólo unos pocos eran ocasionalmente recordados por medio de entrevistas periodísticas y el apelativo de cracks los acompañaba como rememoración a sus años de esplendor. Algunos continuaban ligados como directivos, pero muchos otros seguían sus labores cotidianas y, en términos deportivos, quedaban relegados al olvido. A ello atribuía la prensa el suicidio del jugador Miguel Dellavalle, un sargento de las fuerzas armadas acostumbrado a aparecer en las primeras planas de sus páginas por sus reconocidas destrezas en el campo de juego, que lo llevaron a ser el segundo jugador de la liga local, tras José Lascano, en integrar el seleccionado argentino en matches internacionales. ${ }^{30}$

\section{Los cracks en el profesionalismo}

Con la sanción del profesionalismo en el fútbol cordobés en 1933, se abrió paso a una nueva fase del fútbol como espectáculo a partir de la especialización e incorporación de los jugadores más talentosos al naciente mercado laboral deportivo a través de contratos temporarios de locación de servicios que creaban obligaciones recíprocas para las partes, reconociendo a favor del jugador

${ }^{28}$ La Voz del Interior, 16 de septiembre de 1930, p. 8.

${ }^{29}$ Era una práctica generalizada a través de la que los dirigentes deportivos ofrecían empleo, dinero y otros beneficios materiales a los jugadores de mayor talento para incorporarlos a sus instituciones y formar escuadras más competitivas.

${ }^{30} \mathrm{La}$ Voz del Interior, 23 de noviembre de 1932, p. 13. 
un sueldo o participación en dinero, lo cual era el aspecto específico que lo diferenciaba del amateurismo. La LCF reconocía el derecho de todo jugador a profesionalizar sus actividades, haciendo de sus habilidades y poderío físico un medio de solventar sus necesidades materiales y favorecer su mayor dedicación a fin de mejorar la calidad de los espectáculos que atraían al público que pagaba. ${ }^{31} \mathrm{~A}$ la vez, determinó que los únicos clubes que harían profesionalismo dentro de su organismo serían los de primera e intermedia, mientras que las demás divisiones permanecerían siendo amateurs. ${ }^{32}$ En efecto, sólo 18 de 132 equipos tendrían un plantel conformado por profesionales, por lo que la condición rentada sólo afectó a un pequeño porcentaje de los jugadores.

$\mathrm{Al}$ ofrecer sus servicios a un club a cambio de una remuneración asumieron una precaria condición contractual asalariada y participaron de un incipiente mercado laboral. En la práctica, los futbolistas se transformaron en un nuevo tipo de trabajador, aunque su actividad no fue regulada por el Estado, sino por el ente federativo deportivo, y no se vieron beneficiados por el acceso a derechos propios de la actividad laboral reconocidos legalmente (indemnizaciones por accidentes de trabajo, jubilaciones, entre otros). Dada la fragilidad y volatilidad de su condición, los futbolistas no fueron representados ni se autorreferenciaron como tales, sino que siguieron siéndolo desde su identidad como deportistas talentosos de una actividad que la mayoría seguía concibiendo como un entretenimiento corporal.

Las exigencias del espectáculo futbolístico y el interés de los jugadores por destacarse en las competencias oficiales hicieron que poco a poco empezaran a visualizar la importancia del entrenamiento y el cuidado personal para mejorar su rendimiento. Una preparación más eficaz para la actividad deportiva entraba en tensión con los tiempos del mundo laboral, que podían obstaculizar el pleno desarrollo físico y técnico de los jugadores. La profesionalización resolvió en parte ese problema, aunque la gran mayoría no pudo consagrarse exclusivamente a la práctica deportiva.

Las condiciones sobresalientes de los cracks les permitían negociar por mejores beneficios al momento de ser contratados por un equipo o para permanecer en el que estaban. A decir de la prensa, el amateurismo marrón, pero más concretamente el profesionalismo ya oficializado, había "despertado en chicos y grandes un inmoderado deseo de convertirse en cracks, con miras a

\footnotetext{
${ }^{31}$ Boletín Oficial, núm. 397, 21 de diciembre de 1932. Liga Cordobesa de Football, Argentina.

32 Estatutos, 1935. Liga Cordobesa de Football, Argentina, pp. 4-5.
} 
obtener sueldos más o menos fabulosos -privilegio de quienes se destacan en el arte de la patada-y al pago de elevadas primas por las transferencias a otros clubs". 33

En el imaginario de muchos futbolistas existía la creencia de que las remuneraciones que podían percibir los colocarían en una situación socioeconómica más ventajosa. El fútbol era percibido como una profesión destacada que posibilitaba materializar la idea del ascenso social en una sociedad muy móvil. Como plantea Capistegui (2012, p. 25), la trayectoria de estos héroes populares les abría la esperanza de acceder al éxito social por vías menos ortodoxas como modelo compensatorio, en una negociación de identidades que no lo ponían en conflicto, sino que tendían a integrarlo, dentro de los cánones de la cultura hegemónica.

Pero pronto se revelaría la realidad de un contexto local que no contaba con los recursos para cumplir con esas expectativas, tal como sucedía en la capital porteña. En la mayoría de los casos, los jugadores cordobeses no podían vivir sólo del fútbol ya que el profesionalismo local "apenas llegaba a costear el desayuno", ${ }^{34}$ por lo que tenían otras faenas para ganarse su sustento y el de sus familias. Ellos eran albañiles, joyeros, relojeros, electricistas, vendedores, bomberos, empleados en el mercado, los mataderos o los molinos, guarda de ómnibus, militares, escribientes o adscritos de contadores, entre muchas otras labores; tenían negocios familiares, eran dueños de estaciones de servicios o estudiantes universitarios.

Los jugadores tenían, entonces, sus ocupaciones particulares que conservaban, aunque firmaran contratos profesionales o siguieran actuando como amateurs en algún equipo. En general, la vida deportiva no les representaba más tiempo que el que les acarreaba dos o tres entrenamientos vespertinos durante la semana y el día del partido en el fin de semana. Por ello, la posibilidad de disponer de otro empleo era perfectamente compatible con el trabajo como futbolista rentado. A veces eran el club mismo dentro de sus instalaciones ${ }^{35} \mathrm{o}$ algún dirigente que fuera propietario de un comercio $^{36}$ quienes ofrecían un puesto al jugador, generalmente donde no tuviera un gran derroche de energías. Así, muchos jugadores tenían conciencia de la volatilidad

\footnotetext{
${ }_{33}$ La Voz del Interior, 17 de enero de 1934, p. 3.

${ }^{34}$ Los Principios, 14 de diciembre de 1935, p. 9.

${ }^{35}$ Ratti, de Talleres, trabajaba en la secretaría del club.

${ }^{36}$ L. Merlo, de Peñarol, trabajaba en la farmacia del mercado, cuyos dueños eran el presidente y un dirigente del club.
} 
y caducidad de su condición profesional, por lo que, salvo excepciones, no lo preveían como único sustento, sino como una posibilidad de obtener ingresos extras en una actividad de entretenimiento. A algunos estudiantes les servía también para costearse sus estudios. Para otros que se hallaban en una situación económica más precaria y carecían de empleo en un contexto marcado por la inestabilidad económica y laboral por la crisis de los años treinta, significaba la posibilidad de encontrar un medio de vida, por más efímero que fuera, o un ingreso complementario al de su puesto de trabajo.

Por otro lado, para algunos jugadores de las categorías menores, cuyo concurso no les exigía el mismo grado de especialización que a los profesionales, el fútbol seguía siendo un medio de entretenimiento e intercalaban su participación en los clubes con la práctica de otros deportes. Sixto Pereyra jugaba en Talleres y era capitán de la tercera $\mathrm{D}$, que había conquistado el título; al mismo tiempo, había logrado también los campeonatos de basket de la Federación Cordobesa de Basketball -formando parte del team de intermedia- y de golf en un torneo del club Deportivo Central Córdoba. ${ }^{37}$ También la intervención polideportiva podía desarrollarse simultáneamente en diferentes clubes: Paolucci, arquero de Talleres, boxeaba en clubes barriales; Adolfo Ponce de León era una de las figuras de la cuarta de Belgrano a la par que jugaba pelota a paleta en el club Gimnasia y Esgrima, ${ }^{38}$ lo cual alternaba con sus estudios en la Escuela de Comercio. A otros como Renato Manzoli, la vida académica y su trabajo en el negocio familiar no le dejaban tiempo para intervenir regularmente en el equipo superior de Talleres. ${ }^{39}$ Por el contrario, no eran pocos los que, paralelamente a su intervención en la LCF, participaban de otros torneos como el de los militares o el de las casas comerciales: por citar un ejemplo, el malogrado footballer de Talleres, Camilo Piconne, lo hacía también para Casa Tamburini, de la que era empleado..$^{40}$

Con la emergencia del mercado profesional de jugadores, el "golondrineo" se iba consolidando. En lo que se puede traducir como una postura paternalista, la prensa exceptuaba del escarmiento público que ese comportamiento implicaba a aquellos a quienes "la cotización profesional los llevó a dejar la entidad donde se formaron como una 'legítima ambición del ele-

\footnotetext{
37 Los Principios, 24 de septiembre de 1935, p. 13.

38 Los Principios, 22 de diciembre de 1935, p. 9.

39 Los Principios, 30 de diciembre de 1935, p. 9.

${ }^{40} \mathrm{La}$ Voz del Interior, 22 de octubre de 1931, p. 15.
} 
mento humilde de condiciones"". ${ }^{41}$ Era el caso, entre otros, de dos futbolistas, A. Farías y M. Heredia, que pasaron de la institución que los formó, Lavalle, a Instituto. También de Simón Cuello, de quien se preguntaban ¿por qué, tan "nacionalista" [del club Nacional] como se decía, abandonó sus filas para ir a Talleres? La respuesta esgrimida era que "al muchacho humilde causas poderosas imponían cambiar su actividad, pero aun siempre prima en él el amateur. Continúa siendo un ejemplo viviente de sano deportismo." 42 Ya no se veían el cambio de equipo ni la búsqueda de retribución a través del juego como una inmoralidad, sino como una oportunidad para ciertos sectores de menores recursos. Más que reafirmar la pertenencia a una identidad, la condición de clase de los futbolistas era subsumida dentro de un modelo deportivo que hipotética y circunstancialmente les permitía acceder a una de las fórmulas de éxito social propugnada por la cultura liberal.

Ello no desechaba los comentarios habitualmente sostenidos de que los muchachos formados en el propio club eran los de mejor desempeño porque "sentían los colores de verdad", una forma de incentivar también a que los clubes gastaran menos y prestaran mayor atención a sus divisiones inferiores. Se creía que la adscripción a una pertenencia asociativa primigenia actuaba como un refuerzo emocional que aumentaba la competitividad de los jugadores.

La identificación del profesional como un deportista interesado fue perdiendo validez paulatinamente: la condición rentada pasó a representar no sólo al que obtenía remuneración por su servicio, sino también al que se entrenaba y preparaba regular y sistemáticamente para rendir de manera eficiente en el campo de juego. Considerando que el espectáculo mediatizado se erigía, en parte, a partir del reconocimiento de las estrellas profesionales, el amateurismo encarnaba a quienes no recibían recompensas materiales en el juego, pero fundamentalmente remitía a los que, a pesar de ello, seguían poniendo el mayor entusiasmo, dedicación y nobleza para obtener el triunfo, respetaban a los rivales y los árbitros y defendían con honestidad a sus colores. Era en ese punto en el que empezaron a entrar en contacto: la caballerosidad, un atributo que hacía a la honorabilidad de todo jugador, pasaba a ser también compatible con la práctica rentada; es decir, todo profesional podía tener un "alma" de amateur.

\footnotetext{
${ }^{41}$ La Voz del Interior, 10 de agosto de 1933, p. 14.

${ }^{42}$ La Voz del Interior, 8 de septiembre de 1933, p. 13.
} 


\section{LA HONORABILIDAD PUESTA EN ESCENA}

El honor aparecía configurando la experiencia de los jugadores de fútbol, que competían tanto por el triunfo deportivo, como por el reconocimiento social. Siguiendo a Frydenberg (2011), este era un capital vinculado al "deber ser" que estaba al alcance de todos y que, en muchos casos, era casi el único que tenían, por lo que luchaban por defenderlo e imponer su propio sentido. En otras palabras, era un valor a disposición de todo aquel que participara de la práctica deportiva y que estructuraba sus identidades, modelaba sus conductas e impregnaba cada una de las relaciones de sociabilidad en que se inscribían.

La honorabilidad se custodiaba con la defensa del compromiso identitario asumido a partir de la participación en un club. Además, a pesar de que en los comienzos del fútbol el honor estaba más asociado al fair play, al cumplimiento de las reglas y la aceptación de los resultados, poco a poco se fue abriendo a nuevas experiencias vinculadas al exitismo individual y colectivo: la credibilidad de los procederes del jugador y la fidelidad hacia un equipo eran puestas en cuestión en el marco de una práctica que se iba mercantilizando progresivamente.

La sanción pública que implicaba la exclusión del primer cuadro de un equipo por motivos futbolísticos o extrafutbolísticos o el descrédito como miembros de la elite deportiva eran vividas por los jugadores como ofensas a su dignidad deportiva, ya que entraba en cuestión su compromiso e identificación con un club. Ante ello, algunos optaban por renunciar a su carácter de socio y jugador, tal como hizo el entonces capitán del primer equipo de Instituto, Atilio Borserini. ${ }^{43}$ La misma decisión tomaban cuando eran recriminados por sus propios dirigentes, hinchas o compañeros por un mal rendimiento o alguna jugada desafortunada, hecho que llevó a Paolucci a dimitir como jugador de Talleres al ser culpado por un gol sufrido contra Audax. ${ }^{44}$

A su vez, por esos años se hicieron más usuales algunos hechos que causaban cierto escepticismo en el ambiente deportivo y que ponían en tela de juicio la honestidad de los participantes. El exitismo imperante permeaba cada vez más enérgicamente las estructuras lúdicas y competitivas de la

${ }^{43} \mathrm{La}$ Voz del Interior, 6 de noviembre de 1929, p. 14. Ante esos casos, algunos llegaban a denunciar la intromisión de los directivos en el armado de los equipos toda vez que otros con mayores influencias en "los escritorios" ocupaban su lugar. La Voz del Interior, 29 de octubre de 1930, p. 15.

${ }^{44} \mathrm{La}$ Voz del Interior, 7 de agosto de 1931, p. 10. 
práctica deportiva y los sistemas de valores de los protagonistas, emergiendo nuevas problemáticas en ese escenario. Una de ellas fue la de los sobornos, es decir, del ofrecimiento directo o por vía de un intermediario de dinero, objetos, trabajo u otros incentivos a un jugador, dirigente o réferi a fin de conseguir de ellos un beneficio, un favor o el incumplimiento de sus obligaciones para favorecer a la parte oferente. Hizo su aparición en el ámbito deportivo en los años veinte, aunque fue a partir de la profesionalización del fútbol en los treinta cuando alcanzó mayores repercusiones y se denunciaron con más frecuencia en la prensa o en la LCF algunos hechos sindicados como sospechosos, antideportivos y de mala fe.

Uno de los primeros casos resonantes apuntados en la prensa al respecto fue el que, en junio de 1923, tenía al ex dirigente de Talleres, Adolfo Hanel, como uno de los implicados. Allí se lo acusaba de insinuar al jugador de Instituto, Julio Capitanelli, para que se dejase perder en un partido entre ambos equipos. El diálogo fue presenciado por un dirigente del club albirrojo, quien puso el hecho en conocimiento de las autoridades de su institución y se resolvió la expulsión como socio del jugador. No conforme con ello, Hanel repitió sin éxito su ofrecimiento al arquero de la entidad, Bartolomé Martínez, al que prometió 50 pesos si se dejaba hacer un gol. En declaraciones posteriores y con la asistencia de testigos, los implicados aceptaron la veracidad de los hechos, pero deslindaron sus responsabilidades en el asunto aduciendo que había sido producto de una broma. Con ello pedían una reconsideración de las penas impuestas y, más aún, la recuperación de su honor mancillado ante lo que irrumpía como la mayor de las afrentas a su identidad deportiva. ${ }^{45}$

A veces eran los mismos socios de un club quienes denunciaban a alguno de sus jugadores por conductas que sindicaban como sospechosas, antideportivas y de mala fe para favorecer a un rival; y en esos casos, pedían abrir una investigación en la que, de ser hallados culpables, se determinara su expulsión. Quien sufrió este proceder fue el capitán de la primera división del club Audax, Cristóbal Jara, acusado de beneficiar a Universitario a partir de los siguientes hechos: haber incurrido en muchos foules en el partido, negarse a firmar la planilla $y$, fundamentalmente, haber cedido los puntos al rival cuando faltaban cinco minutos y el partido estaba empatado. Desmentidas las dos primeras acusaciones, en cuanto a la tercera, el jugador afirmó que había sido autorizado a tal medida por miembros de la subcomisión de fútbol

${ }^{45}$ La Voz del Interior, 27 de julio de 1923, p. 11. 
presentes en la cancha, ya que no perjudicaba ni beneficiaba a su cuadro, y que había tenido la conformidad de la mayoría de sus compañeros; la comisión investigadora lo entendió de esa manera y se apoyó en el hecho de que "ceder los puntos y retirar un equipo es un acto común en la vida deportiva, y tan lo es, que en la temporada última y en la disputa de nuestro campeonato, se han dado casos de retirarse equipos estando con score igual, sin que a nadie se le ocurriera ver en cada acto de estos, una violación de preceptos reglamentarios o una actitud contraria a la moral deportiva". ${ }^{46}$

Más allá de la desestimación de la denuncia, el jugador presentó su renuncia indeclinable como socio debido a la campaña difamatoria que se hizo en su contra. Su compromiso con el club había sido puesto en duda por sus propios consocios, quedando expuesta su reputación. Ante esa afrenta, ya no había razón para permanecer en el club depositario de su honor, aun cuando la competencia siguiera revistiendo un costado bien lúdico, como indica el retiro del equipo antes de concluir las partidas.

Si bien no era un tema novedoso por los antecedentes locales y nacionales ${ }^{47}$ en tiempos de actividad deportiva rentada cobraban mayor intensidad las insinuaciones de soborno a jugadores. El afán de ganar partidos y lograr el título de campeonato significaba la posibilidad de percibir mayores ingresos para los jugadores y los clubes, amén del reconocimiento público que tal logro significaba. Apenas conquistado el primer título de la era profesional por Belgrano en 1933, algunos resultados sorpresivos que se habían dado en el torneo dada la campaña de ciertos equipos comenzaron a causar revuelo entre los directivos y aficionados. La prensa sacaba rédito al instalar la polémica en sus páginas y reclamaba una amplia investigación del asunto, que "trastocaba los más elementales principios de ética deportiva". Se decía que los equipos mal colocados o sin nada por disputar entregaban sus partidos con el fin de obtener dividendos extras para paliar o afianzar su situación económica. En este caso, una de las imputaciones recaía en jugadores de Talleres, de quienes se sospechaba que habían sido comprados por un intermediario allegado a Belgrano, quien habría recibido el dinero e informado a los dirigentes albiazules. Creyendo poder comprobar la denuncia con el testimonio

${ }^{46}$ La Voz del Interior, 13 de marzo de 1926, p. 14.

${ }^{47}$ En la prensa se decía que el asunto de los sobornos era embrionario con respecto a lo que sucedía en la Capital Federal, donde tenía larga data. Incluso, a veces allí se culpaba a la policía de que tenía favoritos a quienes, en circunstancias complicadas, les ofrecía una "manito" y suspendía partidos arbitrariamente. La Voz del Interior, 27 de octubre de 1933, p. 12. 
de algunos de los inculpados, las autoridades de Talleres presentaron pruebas ante la LCF y, mientras les abrían expediente, suspendieron por tiempo indeterminado a tres de sus jugadores (Hugo Salvatelli, Rogelio Escatena y Roberto Ortiz). En la resolución emitida, el club decía constatar, al menos, la falta de eficacia y entusiasmo en sus hombres y tomaba esa determinación en salvaguarda del prestigio de la institución y como una satisfacción a la opinión pública y simpatizantes. ${ }^{48} \mathrm{~A}$ su vez, la entidad de Alberdi se defendía de los comentarios "que pretendían restar méritos a su conquista y afectaban su tradición y honestidad deportiva" y dejaba sus libros contables a disposición de las demás instituciones. ${ }^{49}$ Además, suspendió sus relaciones con el clásico rival. Claro está que, de haber existido negociados, nada quedaba registrado y lo que se ponía en juego era la integridad de la palabra.

El otro centro de acusaciones en este acontecimiento fueron los jugadores de Juniors, quienes también tenían oportunidades de título y se la jugaban frente a 9 de Julio. La inesperada derrota generó los rumores circulantes entre algunos asociados y parciales de la entidad de que se habían "vendido", a partir de lo cual el player Hugo Pavoni tomó la determinación de renunciar al club. Inversamente a la reacción de Talleres, la Comisión Directiva de Juniors tomó la resolución de rechazarla "por tratarse de un jugador sumamente culto y caballeresco iniciado en sus filas, donde demostró siempre capacidad y cariño". ${ }^{50} \mathrm{Al}$ mismo tiempo, los compañeros del equipo y numerosos asociados firmaron una nota pública en la que desagraviaban al jugador de esas "calumnias" y le pedían que reviera su decisión..$^{51}$ La renuncia era también un recurso que tenían los jugadores para poder legitimarse, ya que ponían su honorabilidad a juicio de los demás y podían restituirla en el caso de tener una acogida favorable; asimismo, para los directivos, aceptar la renuncia hubiera significado avalar la calumnia, por lo que su desestimación era una forma de salvar el prestigio de la institución y sus jugadores. En tanto dimen-

${ }^{48}$ Los Principios, 28 de octubre de 1933, p. 13. Al año siguiente, al abrirse el periodo de pases, el club tenía la intención de organizar una gira por Santa Fe para llevar a los tres futbolistas suspendidos y, si gustaban, ofrecerlos para ser vendidos. Al poco tiempo, se buscó intercambiarlos a Gimnasia y Esgrima de La Plata en lugar de Farías, por quien los platenses tenían el interés inicial, pero el jugador se negó por su “apego al terruño". La Voz del Interior, 1 de marzo de 1934, p. 14.

${ }^{49}$ Los Principios, 28 de octubre de 1933, p. 13.

${ }^{50} \mathrm{La}$ Voz del Interior, 25 de octubre de 1933, p. 12.

${ }^{51}$ La Voz del Interior, 26 de octubre de 1933, p. 12. 
sión subjetiva de las prácticas sociales, las identidades forjadas por los actores contribuyen a legitimar o deslegitimar sus acciones (Giménez, 2007, p. 50).

Nuevos episodios de ese tipo sacudieron el normal desarrollo de los campeonatos en los años posteriores. En 1934 un jugador de Audax, Giacomelli, fue quien había informado que un desconocido se le acercó -estando él en una vidriera para comprar una corbata-y le insinuó la conveniencia de entregar el partido contra Belgrano. A pesar de que no hubo testigos ni pruebas, este último club decidió no jugar el partido y ceder los puntos a su rival para que no se pusiera en duda el proceder de la institución. En la investigación realizada, la LCF suspendió provisoriamente al jugador de Belgrano Toribio Acosta, que el día del hecho efectuó una visita al jugador Chanes, de Audax, pero fue absuelto al comprobar que existían vínculos personales entre ellos, ya que habían compartido equipo anteriormente en un club de Las Tordillas. ${ }^{52}$

También en los clubes amateurs se producían denuncias de esa calaña, que involucraban a equipos que peleaban el título de segunda división. En Lavalle versus Racing, el presidente de este último sostenía que se había pretendido comprar a su guardavalla. ${ }^{53}$

La recurrencia de hechos semejantes fue motivo para que la LCF tomara cartas en el asunto y decidiera la modificación de su Código de Penas y la creación del Tribunal de Penas, a fin de adaptarlo a las nuevas circunstancias existentes y disponer de instrumentos legales para sancionar a los responsables. Sin embargo, a pesar de esa mayor institucionalización, no siempre se dispuso de pruebas fehacientes para condenar esos hechos. Por ello, los casos de soborno se siguieron reproduciendo a lo largo de esos años. La sospecha generalizada invadía el ambiente en momentos de definición de los torneos y actuaba como vara sobre la que se medía e intervenía ante situaciones que, en otro contexto, no hubieran sido interpretadas de la misma manera. Cuando un jugador de Juniors fue avistado en la secretaría de Belgrano para negociar su pase con dirigentes de este, la comisión directiva del club dueño del pase calificó la situación de insólita, eliminó al futbolista de su plantel y rompió relaciones con la institución rival. ${ }^{54}$ Clubes y jugadores intentaban despegarse de las acusaciones y recurrían a la prensa buscando la exoneración pública. Así, ante la denuncia por el intento de soborno a un jugador de Peñarol, la

\footnotetext{
${ }^{52}$ Los Principios, 17 de mayo de 1934, p. 10.

${ }^{53}$ La Voz del Interior, 14 de diciembre de 1934, p. 14.

${ }^{54}$ La Voz del Interior, 30 de julio de 1939, p. 13.
} 
directiva de Juniors envió una solicitada a los diarios locales aclarando que la persona sindicada como presunto gestor del hecho no era socia del club. ${ }^{55}$

Con el pasar de los años, el Tribunal de Penas fue adquiriendo mayores herramientas y conocimientos para actuar y expedirse en ese tipo de casos. Cuando en 1939 fue pública nuevamente una acusación de soborno, el fallo del ente reconocía la existencia de un ofrecimiento de dinero a jugadores de Audax por parte del presidente, el vicepresidente, el tesorero, el secretario y su hermano y un jugador de primera de Lavalle para que no rindieran un juego normal durante el partido y facilitaran el triunfo del rival. Diferentes sanciones recayeron sobre los implicados y al club infractor se le quitaron los puntos de ese cotejo. ${ }^{56}$ En los siguientes partidos que disputó Lavalle, la desconfianza también se extendió entre sus rivales, quienes temían que las argucias hubieran llegado a los suyos y dudaban de sus lealtades. En efecto, dirigentes y parciales del club Córdoba Central retiraron del campo a un jugador de su propio equipo acusándolo de estar jugando en contra. ${ }^{57}$ Una vez en los "escritorios", la comisión directiva de dicha entidad resolvió suspender por tiempo indeterminado y aplicar una multa de 100 pesos a cuatro jugadores por su deficiente actuación y habérseles comprobado poca voluntad para defender los colores de la institución. La misma sanción le fue impuesta a otro futbolista por jugar en inferioridad física sin avisar a la comisión, mientras que a otros se los suspendió y multó por diferentes razones: actuar con poca voluntad, no presentarse a disputar el partido y no cuidar de su estado atlético. Quienes escaparon a esos castigos fueron felicitados por su demostrada voluntad..$^{58}$

En fin, a todo jugador se le exigía demostrar guapeza, virilidad y empeño, atributos asociados a la identidad masculina en la época, para defender los colores de su club en el campo de juego. En ocasiones, la ausencia de esas virtudes se asociaba rápidamente a la falta de ética deportiva y recaían acusaciones de deshonestidad sobre los implicados por supeditar la recompensa material a la moral deportiva. Las denuncias sembraron de desconfianza el ambiente deportivo y ponían a la honorabilidad en el centro del debate. Así, los valores asociados a la identidad masculina funcionaron como elementos cardinales para medir el compromiso identitario de los jugadores con la enti-

${ }^{55} \mathrm{La}$ Voz del Interior, 14 de agosto de 1936, p. 15.

56 Tribunal de Penas. Libro de Actas, núm. 1, 1939, fs. 209-213. Liga Cordobesa de Football, Argentina.

${ }^{57}$ La Voz del Interior, 20 de noviembre de 1939, p. 12.

${ }^{58} \mathrm{La}$ Voz del Interior, 22 de noviembre de 1939, p. 12. 
dad de la que formaban parte. Entre otras aristas, esos hechos afectaban uno de los principios éticos fundamentales en los que se basaba el fútbol en su dimensión lúdica y competitiva: la igualdad de condiciones de la que partían los rivales, que era un componente esencial del imaginario democrático de los deportes. La sanción de esos ilícitos era una forma de restituir la justicia inicial entre los rivales, tendente a lograr la paridad de condiciones.

Por otro lado, cuando esas virtudes eran apreciadas positivamente a lo largo de la carrera deportiva o dirigencial de un jugador, su figura era objeto de demostraciones públicas. En efecto, en distintas ocasiones fueron homenajeados por parte de socios, allegados y aficionados a un club en reconocimiento de su labor al frente de la entidad y de las cualidades observadas dentro y fuera del campo de juego. Sucedía en momentos en que se celebran algunos hitos en su trayectoria personal, como cuando se despedían de la actividad deportiva o eran designados para cargos prestigiosos de la vida pública. Generalmente eran obsequiados con banquetes en su honor, como al jugador de Belgrano, Antonio Figueroa, a quien agasajaron en el Hotel Córdoba para conmemorar su retiro de la práctica activa del fútbol. ${ }^{59} \mathrm{~A}$ su vez, también se les entregaban medallas de oro o pergaminos como reconocimiento a sus trayectorias, como sucedió con Arturo Orgaz en $1934 .{ }^{60}$ Por otro lado, ante la muerte de figuras reconocidas con un largo recorrido en el ambiente deportivo como futbolistas y dirigentes, las instituciones que los cobijaron decretaban honores a su persona, enviaban ofrendas florales y mandaban representantes a su cortejo. En su honor se hacía un minuto de silencio y los jugadores portaban un brazalete negro, al tiempo que se iniciaban suscripciones para colocar plaquetas con su nombre en locales de la Liga o en el cementerio, como sucedió con Rafael del Caso. ${ }^{61}$ En definitiva, la puesta en escena de esos homenajes actuaba también como un recurso pedagógico para exteriorizar y actualizar los hábitos y valores esperables en toda carrera deportiva, los que debían ser interiorizados por los futbolistas mediante procesos de subjetivación.

\footnotetext{
59 Los Principios, 13 de febrero de 1925, p. 13.

${ }^{60} \mathrm{La}$ Voz del Interior, 1 de septiembre de 1934, p. 14.

${ }^{61} \mathrm{La}$ Voz del Interior, 5 de febrero de 1925, p. 14.
} 


\section{LOS COMPORTAMIENTOS DE LOS JUGADORES EN LOS CAMPOS DE JUEGO}

Con la mayor especialización de los jugadores, los progresos en su entrenamiento físico y táctico y la necesidad de afianzar las construcciones identitarias de cada club, los jugadores fueron sometidos a mayores presiones y exigencias en un campo de juego. La honorabilidad se defendía con el éxito deportivo, para lo que se debía emplear el mayor talento, empeño y tenacidad posibles. Ese mayor ímpetu manifestado en las canchas, que se entendía también a partir de la misma dinámica catártica del deporte, daba margen a un aumento en el juego brusco, los golpes y agravios entre colegas y hacia árbitros y público, las discrepancias y desobediencia hacia los árbitros o el abandono de los campos de juego por parte de los futbolistas.

Todos estos eran medios que tenían los jugadores para reponerse ante una adversidad $\mathrm{u}$ obtener superioridad ante un rival, evitar lo que juzgaban como una arbitrariedad en una derrota y amparar una identidad que estaba en peligro. Era su honor el que estaba en juego a través de la defensa de lo que consideraban justo, así como de la legitimidad de la reacción ante lo que se creía injusto. Incumplir las reglas o desconfiar de la ecuanimidad de los fallos de los árbitros eran parte del repertorio de quienes, ante un escenario desfavorable, no podían asumir el desequilibrio de las condiciones iniciales de igualdad que aseguraba el juego y manejaban otras nociones acerca de lo que era justo u honorable (Frydenberg, 2011, p. 81).

Semana tras semana las crónicas deportivas relataban los incidentes generados entre rivales tanto en el fútbol aficionado como en el oficial, a la vez que la LCF recogía y publicaba las notas de protestas levantadas por los clubes. Por ejemplo, en un mismo domingo de mayo de 1933, la prensa relataba sucesos que se habían producido en los dos encuentros más trascendentales de la jornada. Por un lado, en el encuentro que disputaban Belgrano y Peñarol en la cancha de la Liga, donde venía primando la brusquedad en las acciones de los jugadores, un futbolista de la cuarta división de Peñarol que presenciaba el partido como espectador provocó a uno de los jugadores rivales tras el gol del empate de su equipo, originándose de inmediato una gran batahola entre ambos planteles y uno que otro particular; la policía controló la situación, aunque dos jugadores de Belgrano resultaron heridos. El otro episodio ocurrido en el estadio de Talleres fue provocado por la reacción de un jugador local contra un rival y el árbitro asistente de estos ante un foul del 
que fue víctima, que terminó en una pelea generalizada entre los dos equipos. Una vez expulsados los dos mayores implicados, fuera del campo de juego continuaron agrediéndose. ${ }^{62}$

La intolerancia a la derrota también abarcaba a los equipos de divisiones menores de las ligas aficionadas. Por ejemplo, dirigentes del club Once Corazones acusaron públicamente la actitud sostenida por su similar Farmacia Güemes, quienes una vez vencidos apedrearon a sus rivales, robaron la pelota de su propiedad y se dieron a la fuga. ${ }^{63}$

Ante la sucesión de hechos de indisciplina, las entidades deportivas no sólo recurrieron a sus propios reglamentos internos para sancionar a aquellos miembros que lesionaban sus intereses, sino que desde finales de la década de 1920 se encomendaron a otros mecanismos para actuar sobre su prevención. En efecto, la Liga resolvió que todo cuadro que alistara a jugadores procesados judicialmente sería penado. Para adecuarse a la medida, cada club empezó a realizar una investigación al momento de admitir un socio para averiguar los antecedentes del interesado y evitar el ingreso de "elementos indeseados", por lo que solicitaba certificados de conducta en la policía. Como ello requería la obtención de la Cédula de Identidad Policial, cuyo costo no todos los interesados estaban en condiciones de atender, la LCF solicitaba de aquella institución su obtención gratuita, alegando que no tenía los fondos para afrontarla y que la mayoría de los jugadores eran de condición humilde y de escasos recursos. ${ }^{64}$ Las instituciones deportivas encontraron en esto una forma de ejercer mayor control y selectividad sobre sus recursos humanos, excluyendo preventivamente y estableciendo nuevas distancias a quienes no reunían los parámetros de conducta esperables por las autoridades.

A su vez, los organismos disciplinarios de la Liga fueron progresivamente aceitando los dispositivos de sanción e imponiendo penas cada vez más severas a quienes intervenían en ellos. El cuadro 1 refleja estadísticamente la gran cantidad de acciones controversiales de jugadores y dirigentes en los campos de juego que el Consejo Directivo de la LCF castigaba anualmente. Por ejemplo, en un partido de tercera categoría entre Audax y Huracán en el que el árbitro del cotejo fue agredido y despojado de sus artículos personales por parte de los miembros del primero, las autoridades de la Liga suspendieron

\footnotetext{
${ }^{62} \mathrm{La}$ Voz del Interior, 20 de mayo de 1933, p. 13.

${ }^{63} \mathrm{La}$ Voz del Interior, 21 de septiembre de 1933, p. 13.

${ }^{64} \mathrm{La}$ Voz del Interior, 12 de enero de 1929, p. 15.
} 


\section{Cuadro 1. Cantidad de hechos penados anualmente por la Liga Cordobesa de Fútbol a jugadores y dirigentes}

$\begin{array}{ll}\text { Año } & \text { Penas } \\ & \\ 1927 & 159 \\ 1928 & 173 \\ 1929 & 121 \\ 1930 & 225 \\ 1931 & 199 \\ 1932 & 161 \\ 1933 & 131 \\ 1934 & 126 \\ 1935 & 108 \\ 1936 & 217 \\ 1937 & 148 \\ 1938 & 171 \\ 1939 & 173\end{array}$

Fuente: elaboración propia sobre la base de datos suministrados por Libro de penas a jugadores, dirigentes y referees. 1927-1940, Liga Cordobesa de Football, Argentina.

a todos los jugadores del equipo por el término de seis meses y a su capitán, principal responsable del hecho, por un año. ${ }^{65} \mathrm{~A}$ su vez, a los jugadores que reincidían en la provocación de escándalos se les prohibía, con la anuencia de la policía, la entrada a las canchas.

En más de una ocasión, los árbitros aunaron posiciones exigiendo mayores seguridades y rechazaron dirigir a ciertos equipos, fundando su decisión en las protestas y malos hábitos de los jugadores y las incorrecciones de su parcialidad. Por otro lado, poniendo foco más en la prevención, dictaron conferencias sobre leyes y comportamientos en el juego, incluso invitando a árbitros nacionales, pero la concurrencia de jugadores y dirigentes era escasa.

La necesidad de moralizar y civilizar el deporte se imponía entonces como meta también de ciertos sectores de la prensa. Por ello, desde sus páginas se lanzaban máximas con las conductas esperadas de los jugadores,

${ }^{65}$ La Voz del Interior, 4 de junio de 1935, p. 15. 
donde se los conminaba a saber ganar con modestia y perder con dignidad, a respetar a los rivales y acatar las decisiones de los árbitros. Los procederes de los jóvenes deportistas eran reprimidos, incluso, desde instancias previas y posteriores a su estadía en un campo de juego; es decir, desde el momento mismo en que se dirigían o retornaban de esos recintos haciendo uso de transportes públicos, se cuestionaban sus expresiones de júbilo ajenas a la "urbanidad" deseada, como los silbidos o los cánticos en voz alta. La pedagogía civilizadora les exigía mayor recato y mejor educación a esos muchachos.

Los periódicos exaltaban como "caballeros del deporte" a aquellos futbolistas como Federico Fatechi que nunca habían sufrido pena disciplinaria alguna por promover un incidente o ser expulsado de un campo de juego. La descripción aseguraba que eran contados los que se encontraban en una situación análoga, por lo que ese integrante del plantel de Instituto y escribiente en la Dirección de Estadística de la Provincia gozaba de alto concepto entre los allegados a su club y la masa deportiva general. ${ }^{66}$ Por el contrario, quienes eran inculpados por cualquier tipo de indisciplina aparecían públicamente escarmentados. Los jugadores, que veían en ello una ofensa a su dignidad personal, se comunicaban con las redacciones locales para desligarse $u$ ofrecer explicaciones de asuntos en los que figuraban como protagonistas y quedaba su honor mancillado. Cuando estas atribuciones identitarias conferidas externamente tomaban carácter público, tenían una función estigmatizadora de las prácticas de los sujetos y condicionaban su actuación en el campo. A veces, ello derivaba en enfrentamientos directos con la prensa, involucrando también al club del que el futbolista formaba parte. En efecto, en el entretiempo de un partido jugado contra Juniors en abril de 1934, el jugador Demetrio Aguirre de Talleres insultó públicamente a los cronistas instalados en el palco de prensa, disgustado por el trato negativo que usualmente recibía en los comentarios periodísticos. A modo de desagravio, el Centro de Cronistas Deportivos exigió una reparación al jugador y a las autoridades de su club la sanción correspondiente. Hasta que no se satisfizo su demanda, los diarios locales Los Principios, La Voz del Interior, Córdoba y El País cerraron sus columnas a toda referencia que reflejara las actividades futbolísticas de la entidad. El entredicho duró una semana, hasta que, tras una reunión entre las partes y el presidente de la LCF, quedó zanjado con la decisión de Talleres de suspender a su jugador, quien no volvió a jugar por el resto de la temporada y al año

${ }^{66}$ La Voz del Interior, 12 de septiembre de 1935, p. 14. 
siguiente fue transferido a Gimnasia y Esgrima de Rosario. ${ }^{67}$ El asunto reveló los serios inconvenientes que significaba la falta de información a los aficionados para el normal desenvolvimiento de las actividades de la institución, lo que también le traía aparejado consecuencias económicas. El escrache público o la desatención informativa podían convertirse en peligrosos factores de desestabilización y deslegitimación de las asociaciones y sus miembros. Ello dejaba ver el poder que tenía la prensa para asegurar la reproducción del espectáculo deportivo, ya que era el medio que mantenía anoticiados a todos sus participantes. Al respecto, además de informar sobre los sucesos deportivos, en sus páginas se proponía el intercambio de ideas y preferencias con el lector aficionado ${ }^{68} \mathrm{y}$ se inauguraban apartados para evacuar sus consultas $o$ amparar réplicas u opiniones por medio de cartas dirigidas al diario. Así, se abría un espacio de discusión y crítica libre, colectivo y relativamente igualitario -siempre y cuando se supiera leer y escribir y los contenidos superaran el filtro del perfil editorial- a través del que la prensa se fue constituyendo en un factor de presión ineludible en la toma de decisiones. A su vez, en la polémica, los incidentes y las rivalidades, esta encontró una estrategia para captar más público y generar mayores intercambios con el lector. En algunos casos, dado que los cronistas pertenecían o mantenían afinidades con clubes locales, se generaban sospechas en cuanto a las preferencias expresadas en las notas o en la cobertura dada ${ }^{69}$ por lo que desde el Centro de Cronistas Deportivos se conminaba a sus asociados a que observaran mayor imparcialidad en los escritos que remitían. Paralelamente, los medios aducían sufrir presiones por parte de los clubes y aficionados que intentaban manipular la prédica de los cronistas de acuerdo con sus pretensiones e intereses.

A veces eran los mismos jugadores quienes ejercían como detentores de la honorabilidad y procedían a su resguardo. En efecto, hubo ocasiones en que, cuando un equipo hacía uso reiterado del juego brusco u otras artimañas para vencer a un rival, estos últimos preferían retirar su equipo y perder los

${ }^{67}$ Los Principios, 15 de abril de 1934, p. 9 y 27 de abril de 1934, p. 9; Libro de penas a jugadores, dirigentes y referees, 1934, pp. 98-99. Liga Cordobesa de Football, Argentina.

${ }^{68}$ Mayoritariamente, eran jóvenes varones con una presencia activa en los ámbitos deportivos (jugadores, socios, dirigentes y árbitros) que poco a poco fueron disponiendo de mayores competencias culturales como para acceder a la lectura e interactuar públicamente con colegas y cronistas.

${ }^{69}$ Los Principios, 30 de diciembre de 1924, p. 9. 
puntos para que no fueran merecedores del honor de jugar contra ellos. ${ }^{70}$ Asimismo, cuando un club aceptaba un desafío contra un rival desconocido, al llegar al lugar del encuentro podían encontrarse con manifestaciones hostiles hacia su presencia por parte de jugadores y barras rivales. Ello era motivo para que algunos terminaran eludiendo el compromiso y difundiendo los hechos en la prensa para evitar que otros sufrieran las mismas vicisitudes. Sin embargo, ese relato era también pergeñado por quienes habían sufrido una derrota e intentaban justificarla o deslegitimar el triunfo rival. La desmentida pública del difamado no tardaba en llegar y para dejar sentada su caballerosidad deportiva ponían como garantes a los vecinos del barrio y los otros equipos que los habían visitado. Eran estas formas de sanción popular contra un accionar calificado como violento o agresivo en ámbitos donde no había penetrado la mediación de instituciones disciplinarias.

Más allá de que la prensa y los comunicados de las instituciones deportivas recrearan un clima de permanente enfrentamiento y conspiración, otros eran los valores que se experimentaban la mayor parte del tiempo en el ambiente deportivo y permitían la reproducción cotidiana de su práctica asociativa. Al respecto, la lealtad y la camaradería siguieron regulando los vínculos e intercambios de los grupos de muchachos y ejercieron como elementos de cohesión de todos aquellos que se incorporaban a equipos ya armados o que se reunían para formar uno nuevo y poder competir contra otros semejantes en torneos regulares. Incluso esas virtudes podían aparecer mediando las rivalidades más fuertes. El enfrentamiento entre Talleres y Belgrano era el que más apasionaba a los cordobeses porque eran los equipos que se disputaban la supremacía local: "es un compromiso de honor", en el que se festejaba la derrota del otro, tanto como la victoria propia. Más de una vez hubo conflictos entre las partes que derivaron en rupturas de las relaciones, lo que privaba al fútbol local de sus enfrentamientos fuera de los que ya estaban establecidos por la programación oficial del campeonato. ${ }^{71}$ Sin embargo, la rivalidad también tenía sus momentos de cordialidad mutua, como cuando en una final entre ambos, Talleres se adjudicó el título de campeón y su vuelta olímpica en

70 La Voz del Interior, 4 de diciembre de 1924, p. 14.

${ }^{71}$ En una de ellas, a principios de 1934, debieron intervenir en la solución del conflicto el ministro de Obras Públicas de la provincia, Eduardo Deheza, el jefe de la delegación porteña del seleccionado de la Asociación Argentina, las autoridades de San Lorenzo de Almagro que estaban de visita en la ciudad y deportistas amigos de ambas instituciones. La Voz del Interior, 28 de marzo de 1934, p. 14. 
la cancha fue acompañada por los jugadores de Belgrano ante la ovación del público. ${ }^{72}$ Eran momentos de confraternidad entre los jugadores de los clubes que mostraban la pervivencia de ciertas tradiciones asociadas al fair play. Aunque ese modelo entró en tensión y sufrió ciertos deslizamientos con el profesionalismo, no desapareció totalmente, ya que pervivió como referencia moral ante el avance de la lógica mercantilista en el fútbol.

\section{CONCLUSIÓN}

El proceso de espectacularización y mercantilización que vivió el fútbol en las décadas de los años veinte y treinta implicó una serie de transformaciones en las formas en que la sociedad cordobesa se apropió de esa práctica. En la experiencia de jugar y asociarse, los sujetos vivieron una práctica socializadora y asumieron nuevos roles, hábitos, estrategias y comportamientos que afectaron sus vínculos identitarios personales y colectivos.

La mayoría de los jóvenes jugaba para entretenerse y se fueron acomodando de acuerdo con sus posibilidades e intereses en los diferentes clubes y categorías de la competencia oficial o aficionada. Algunos pocos tuvieron la oportunidad, además, de obtener ingresos por su desempeño deportivo, lo que acentuó el nomadismo deportivo ya existente en los jugadores, que los llevaba a pasar de un club a otro procurando mejores oportunidades. Así, el ideal romántico basado en la lealtad emocional a identidades futbolísticas primigenias se fue diluyendo frente al pragmatismo mercantilista que suponía el fenómeno del "golondrineo". Se trató de un proceso conflictivo y fluctuante, en el que los sujetos negociaron y confrontaron en sus prácticas con discursos portadores de representaciones desde los cuales se asumieron y actuaron en el universo deportivo. De esta manera, los jugadores subjetivaron identidades diversas y cambiantes a través de las que se referenciaron, legitimaron o deslegitimaron sus acciones y forjaron nuevos sentidos de pertenencia dentro de los límites y posibilidades que imponían las estructuras sociales.

En ese contexto se fue construyendo alrededor del fútbol un trayecto modélico en el que los muchachos que se iniciaban en los potreros de la ciudad tenían como horizonte descollar en un círculo privilegiado que ofrecía gratificaciones materiales y simbólicas a sus integrantes. En ese proceso, re-

${ }^{72}$ La Voz del Interior, 13 de noviembre de 1939, p. 12. 
configuraron sus identidades y proyectaron un camino alternativo de ascenso social dentro de la lógica capitalista, pero en la mayoría de los casos ello se diluía como una mera aspiración. El mérito deportivo funcionó como elemento selectivo y distintivo y alimentó el desarrollo de los cracks como objetos culturales de consumo, en función de las representaciones legitimadas por el público y fomentadas por la prensa. Sin embargo, dadas las transformaciones a las que se vio sometida la práctica deportiva, su construcción identitaria estuvo en constante renovación, desde una connotación más negativa a un perfil multifacético asociado con el mundo del trabajo.

En cada partido, los jugadores ponían en juego no sólo un resultado deportivo, sino el reconocimiento social y la pertenencia a un colectivo, por lo que su honor estaba cada vez más asociado a la búsqueda del triunfo. En el fragor de la competencia, su dinámica catártica, su empeño exitista y la recreación de las rivalidades volvieron más frecuentes en determinados momentos los hechos de violencia, agresividad y corruptibilidad. Estos fueron medios al alcance de los jugadores para alcanzar los objetivos, reponer la justicia que consideraban les había sido arrebatada y defender, de este modo, la honorabilidad depositaria de su identidad. Sin embargo, los jugadores no pasaron la mayor parte de su tiempo agrediendo, complotando o amedrentando, sino compartiendo y confraternizando con sus pares una actividad a la cual entregaron parte de su tiempo, sus relaciones y su repertorio identitario.

En definitiva, el análisis de esta práctica social nos permite comprender de una manera un poco más integral las diversas experiencias de modernidad vividas por estos sujetos en una sociedad en transformación, a través de la que fueron asumiendo identidades de manera fragmentaria y creativa en articulación con los capitales acumulados en otras áreas de su vida cotidiana.

\section{LISTA DE REFERENCIAS}

Archetti, E. (2008). El potrero y el pibe. Territorio y pertenencia en el imaginario del fútbol argentino. Horizontes Antropológicos, 14(30), 259-282. Dor http://dx.doi. org/10.1590/S0104-71832008000200013

Baker, E. y Castro, D. (2008). Presentación. Espectáculos en la España contemporánea: de lo artesanal a la cultura de masas. Revista Ayer, 72, 13-26. Recuperado de https://www.ahistcon.org/PDF/numeros/ayer72_EspectaculoSociedadEspa\%C3\%B1aContemporanea_Baker_Castro.pdf 
Bolufer, M. y Morant, I. (2012). Identidades vividas, identidades atribuidas. En P. Pérez-Fuentes (ed.), Entre dos orillas: las mujeres en la historia de España y América Latina (pp. 317-352). Barcelona: Icaria.

Capistegui, F. (2012). Deporte e identidad, o sobre cómo definirnos. Historia y Comunicación Social, 17, 19-39.

Di Giano, R. (2004). El fútbol de elite y su reapropiación por los sectores populares. En H. Biagini y A. Roig (dir.), El pensamiento alternativo en la Argentina del s. Xx. Tomo I: Identidad, utopía e integración (1900-1930) (pp. 211-217). Buenos Aires: Biblos.

Frydenberg, J. (2011). Historia social del fútbol. Desde el amateurismo al profesionalismo. Buenos Aires: Sudamericana.

Giménez, G. (2007). Estudios sobre la cultura y las identidades sociales. México: Intersecciones.

Kaliman, R. (comp.) (2013). Sociología de las identidades. Conceptos para el estudio de la reproducción y la transformación cultural. San Salvador de Jujuy y Villa María: Ediunju/Eduvim.

Ortiz Bergia, M. J., Reyna F., Portelli, M. B., Moretti, N. (2015). Procesos amplios, miradas locales: una historia de Córdoba entre 1880 y 1955. Córdoba: Centro de Estudios Históricos "Prof. Carlos S. A. Segreti".

Pérez Ledesma, M. (2008). La construcción de las identidades sociales. En J. Beramendi y M. J. Baz (eds.), Identidades y memorias imaginadas (pp. 19-42). Valencia: Publicacions de la Universitat de Valencia.

Reyna, F. (2015). La difusión y apropiación del fútbol en el proceso de modernización en Córdoba (1900-1943). Actores, prácticas, representaciones e identidades sociales. Córdoba: Universidad Nacional de Córdoba.

Romero, J. L. (1995). Los sectores populares urbanos como sujetos históricos. En L. Gutiérrez y J. L. Romero, Sectores populares, cultura y política. Buenos Aires en la entreguerra (pp. 25-46). Buenos Aires: Sudamericana.

Villena Fiengo, S. (2003). El fútbol y las identidades. Prólogo a los estudios latinoamericanos. En P. Alabarces, Futbologías: fútbol, identidad y violencia en América Latina (pp. 21-35). Buenos Aires: Clacso. 